\begin{tabular}{|c|c|c|}
\hline BENTHAM OPEN & The Open Civil Engineering Journal & $\begin{array}{l}\text { The Open } \\
\text { Crill Engine. }\end{array}$ \\
\hline CrossMark & Content list available at: www.benthamopen.com/TOCIEJ/ & स्रात्व \\
\hline & DOI: $10.2174 / 1874149501711010867$ & \\
\hline
\end{tabular}

REVIEW ARTICLE

\title{
State-of-the-Art of Research on Damage Mechanism and Mechanical Property of the Composite Structures after Exposure to Fire
}

\author{
Chunyang Liu ${ }^{1, *}$, Yuzhuo Wang ${ }^{1}$, Xin Liu², Dabin Yang ${ }^{1}$ and Xiuli $\mathrm{Du}^{3}$ \\ ${ }^{I}$ College of Civil Engineering of Shandong Jianzhu University, Jinan 250101, China \\ ${ }^{2}$ College of Civil Engineering, Tongii University, Shanghai 200292, China \\ ${ }^{3}$ College of Civil Engineering, Beijing University of Technology, Beijing, 100124, China
}

Received: February 13, 2017

Revised: April 10, 2017

Accepted: April 30, 2017

\section{Abstract:}

\section{Introduction:}

Based on the comparative and analytical studies on the research work conducted on the damage mechanism and mechanical property of the composite structure after exposure to fire, the research method and the research achievements are summarized and reviewed.

\section{Results and Conclusion:}

The achievements are mainly obtained from the studies on the beam (floor-slab) component, beam-column joints and the frame structure by the means of the axial compression static experiment or quasi static experiment in the past. Finally, some issues that still need to be studied are also discussed from three prospects.

Keywords: After Exposure to Fire, Post-high Temperature, Damage Mechanism, Mechanical Property, Seismic Capacity, Composite Structures.

\section{INTRODUCTION}

Fire has become one of the major disasters which endanger people's life and property safety. In all kinds of fire accidents, the number of building fire is the largest. The damage and collapse of building structure is the main reason for the huge economic losses and casualties. Such as the 2001 "9.11" event, two 110 - storey towers of the world trade center in New York collapsed in succession in the fire caused by plane crash. And in April 2013, Xiangyang, Hubei, a hotel fire caused a total of 61 casualties. In October 2013, Shijing Mountain, Beijing, two fire brigades died in the line of duty and great damage to property was caused in the fire of Xilongduo mall. In December 2013, Yuexiu District, Guangzhou, Jianye Building (a 25-layer building) was burned clean form, the tenth layer to the top, caused huge property losses.

In order to improve the safety of the structures under fire and reduce the loss caused by fire on people's social life and casualties, in recent years, researchers have carried out extensive research on the mechanical properties of building structures under fire (high temperature). In traditional combination structure, the steel reinforced concrete structure (SRC structure) and Concrete-Filled Tubular structure (CFT structure), which have good mechanical performance and economic performance, have been widely used in High-rise, super high-rise and complex high-rise buildings. China has become the fastest developing country of high-rise and super high-rise building in the world. Composite structure will be more widely used in engineering by the good performance above. Building structure will lead to different degrees of damage under different fire environment. The damage accumulated to a certain degree will cause collapse. Conversely,

\footnotetext{
* Address correspondence to this author at the College of Civil Engineering, Shandong Jianzhu University, Jinan, Shandong, 250101, China; Tel: +8613869113665; E-mail :liucy2011@sdjzu.edu.cn.
} 
if the damage was accumulated to a lower degree, the building structure can maintain normal function after reinforcing and repairing according to the feasible plan which is put forward by the designers.

In this paper, the research results of composite structures damage mechanism and mechanical property after exposure to fire are discussed, according to the main line of the basic component to the joint and then to the overall structure. Existing problems and development trend are also analyzed.

\section{GENERAL RESEARCH ON COMPOSITE STRUCTURAL COMPONENTS}

\subsection{Composite Beam and Plate Element}

Static test results on the mechanical properties of seven groups of steel reinforced concrete beams were reported in reference [1]. The study results indicated that the failure mode of the specimen after exposure to fire was similar to that in room temperature, but the shear cracks on the beam web appeared earlier. The plane cross-section assumption could be satisfied at initial loading stage for the beams which failed flexibly. However, the strain distribution along the section height was not satisfying linear relationship when the load was over 80 percent of the limit loads. Compared with the bearing capacity in room temperature, the shear strength and bending strength after exposure to fire reduced about 15 percent and 17.5 percent in average, respectively. Numerical simulating analysis was launched in reference [2] to study the residual bearing capacity of the steel reinforced concrete beams after exposure to fire. Furthermore, the parameter such as concrete strength, shear span ratio, section steel ratio and temperature elevating time was selected and its influence to the residual bearing capacity after exposure to ISO834 standard fire was analyzed by using FEM. The results showed that the ultimate strength of steel reinforced concrete beams after exposure to ISO834 standard fire reduced obviously as compared with that in room temperature. The residual strength could be influenced by the temperature elevating time in a large degree, and the residual strength could reduce to 68 percent of that in room temperature after $120 \mathrm{~min}$. With the increase of shear span ratio and section steel ratio, the residual strength could also increase. However, the residual strength was not sensitivity to the concrete strength. Experiments on nine groups of prestressed steel reinforced concrete simple-supported beam were carried out in reference [3] to study their mechanical properties under fire and after exposure to fire. The influence of the parameter, such as fire temperature effect time, degree of pre-stress, to the bearing capacity of the beam was studied and the simplified calculation method for calculating the residual strength of the pre-stressed beam was also proposed based on the equivalent section method. The results showed that the crack development rule was similar to that in room temperature, but the crack load reduced clearly. And the mid-span deflection of the beam under the same loading level would increase obviously as the fire temperature effect time went on. Furthermore, the mid-span deflection would decrease when the degree of the pre-stress was larger. For the exist of the pre-stress, the beam also had good crack closing capacity. Experiments on fourteen groups of pre-stressed steel reinforced concrete simple-supported beam were carried out in reference [4]. During the fire test process, the load was applied on the pre-stressed SRC beam for some specimen, then the static loading test was carried on. Based on the finite element method, the normal bending capacity calculation method for the pre-stressed SRC beam after exposure to fire was established. The results showed good agreement with the experiment results. Considering the material properties at high temperature, the crack width calculation method was also proposed. An experimental study was carried on in reference [5] to understand the mechanical behavior of the ceramsite concrete composite floor after exposure to fire. The results found that the failure mode of the steel sheet-ceramsite concrete composite floor after fire was different from that in room temperature. The post-fire bearing capacity of the slab was only 60 percent of that in room temperature. And the residual strength of the slab after exposure to fire would increase as its thickness increased. However, this residual strength of the slab would reduce obviously for the exist of stud which was welded on the steel sheet. Considering this point, small studs should not be used to enhancing the strength of the composite plate element in practical projects. Furthermore, the mechanical behavior of the slab in a structure was indeed different to that in experiment condition, for the binding effect from the beams around the slab. And the redistribution of the internal force would take place for the interaction between beam and slab during the process of fire. Therefore, the evaluation methodology for mechanical behavior of the constrained floor slab after exposure to fire should be developed in the future.

\subsection{Composite Column}

The concrete filled steel tubular column and steel reinforced concrete column were applied in high rise and ultrahigh rise buildings for their good seismic performance. The mechanical performance and failure mechanism study of the composite column after exposure to fire would have large significance to the buildings reconstruction after exposure 
to fire. Twelve specimens which cross section is circular or square were designed to study the residual bearing capacity after exposure to the standard ISO-834 and China standard GB9978-88 fire in the reference [6, 7]. The study results indicated that the failure mode of the specimen after exposure to fire was similar to that in room temperature; the residual strength of the column was obviously lower than the strength in room temperature. The load eccentricity ratio has a little influence on residual strength of column after exposure to high temperature. The load-displacement curve after exposure to standard fire through theoretical analysis in the reference $[8,9]$, then the parameters of steel ratio, concrete strength grade, load eccentricity ratio were chosen in the analysis of residual strength after exposure to fire. The results showed that the main factors affect the residual strength of concrete filled steel tubular columns were slenderness ratio, the time exposure to fire and the thickness of the protective layer. Finally, the simplified evaluation method for residual strength of the composite columns after exposure to fire was proposed. The static test was conducted in reference $[10,11]$ on the concrete filled steel rectangular tubular columns after exposure to the ISO-834 standard fire. Then the expand analysis and theoretical analysis were launched, and the residual strength coefficient formula which was used to evaluate the bearing capacity of the concrete filled steel tubular columns after exposure to fire was determined by regression analysis. The calculation parameters of the axial compression strength of the concrete filled steel tubular column after exposure to fire was studied based on numerical analysis in reference [12]. Then the residual axial compression strength of the concrete filled steel tubular columns was calculated after the feature points of axial compression constitutive curve and the coefficient of equivalent restraint effect was determined. Furthermore, At the simplified moment curvature model was given when the feature points on moment-curvature relation curve was determined by the numerical analysis method. The influence coefficient formula to evaluate the ultimate strength of the concrete filled steel square tubular column with or without fire- protection layer and concrete protection layer was provided in reference [13]. Experiment on three steel reinforced concrete column with inner circular steel tubular was carried out in reference [14 - 16]. The residual axial compression strength after exposure to high temperature was also studied. The influence coefficient of the residual strength was calculated by using the computer program. And the parameters which could influence the residual strength coefficient such as fire duration time, longitudinal reinforcement ratio, position coefficient, section size were chosen to make an extended analysis, it is regarded that the longer time exposed to fire, the more residual strength decreased. In addition, the larger position coefficient and the greater section dimension could result in higher residual strength coefficient. The mechanical property of the centrifugal concrete filled steel tubular column after exposure to fire was studied based on the finite element analysis in reference [17]. The numerical model was fired uniformly on four faces. The study results found that there was no obvious elastic stage and plastic stage in the load-deformation curve, and the curve is basically a diagonal straight line in the whole process. With the time exposure to fire increased, the bearing capacity dropped and the maximum strain value also decreased. When the temperature exceed $900^{\circ} \mathrm{C}$, the residual strength of the specimen almost was zero. Moreover, the residual strength evaluation method for the centrifugal concrete filled steel tubular short column after exposure to the standard fire was proposed. The temperature field distribution of the steel reinforced concrete column during the rising and dropping process of the temperature was analyzed in reference [18]. The maximum temperature of each node was also obtained by the program. The load-strain curves of the steel reinforced concrete column under axial compression was calculated after the results of the maximum temperature were read into the numerical model. The residual strength of the steel reinforced concrete column after exposure to fire was influenced in a large degree by parameters of the section dimension, steel ratio, fire duration time and slenderness ratio compared with the parameters of the steel type, the concrete strength grade. Experiment on two H-section steel reinforced concrete eccentric compression column under ISO-834 standard fire was launched in reference [19]. The results showed that the residual strength of the steel reinforced concrete composite column was greatly affected by the fire load ratio. The static loading test was conducted on eight $\mathrm{H}$-section steel reinforced concrete columns after exposure to fire in reference [20, 21]. The results indicated that the failure mode of the specimen after exposure to fire was similar to that in room temperature, and the residual strength of the column decreased obviously. The quasi-static test on concrete filled steel tubular column after exposure to fire was conducted in reference [22 - 24]. The results found that the column showed good energy dissipation capacity and deformation capacity. However, the energy dissipation capacity of column with circle cross section is better than the column with square cross section. A fuel gas and electricity composite heating method was put forward in reference $[25,26]$. The quasi-static test on nine concrete filled steel tubular columns after exposure to fire was carried out using this method. The results indicated that the column showed good ductility and energy dissipation capacity both at room temperature and after exposure to fire. Compared with the column in room temperature condition, the energy dissipation capacity and deformation capacity improved and the bearing capacity and the stiffness of the column decreased after exposure to fire. 


\section{GENERAL RESEARCH ON COMPOSITE STRUCTRAL JIONTS AND FRAME}

Beam-column joints are the key parts of the structure system. Research on the mechanical properties,seismic behavior and damage evolution rule of the joint after exposure to fire (high temperature) could provide a scientific basis for the establishment of performance evaluation. Some achievements were obtained through the experimental study and theoretical analysis. Seismic performance tests were carried on fourteen concrete filled tubular column and steel beam joints with outer concentric annular-stiffer in reference $[27,28]$. The influence on the ductility and energy dissipation property of the parameters including the section types, the fire duration time, the beam-column stiffness ratio is discussed. The results showed that, compared with the concrete-filled circular steel tubes, concrete-filled square steel tube joint is easy to have steel tube buckling and the cracks. Then its deformation and energy dissipation capacity decreased for this. However, the ductility and energy dissipation capacity of the joint, which has bigger linear stiffness ratio of beam-column and longer fire duration time, are improved. In addition,nonlinear finite element model which could be applied to the analysis of force-displacement of the joint after exposure to fire is proposed. Moreover, geometric and physical nonlinearity were considered in this model. Experimental study and finite element analysis were launched on three concrete filled steel tubular column-composite beam joints and three steel reinforced concrete column-steel reinforced concrete beams joints in reference [29]. The results showed that the ultimate bending strength of the joint after exposure to fire is lower than that in room temperature. And the influence of cooling process on concrete filled steel tubular column-composite beam joint is bigger than steel reinforced concrete column-steel reinforced concrete beam joint. It was also recommended that the performance assessment of the post-fire joint should consider the effects of temperature and loading path. Finite element analysis by using the software of ABAQUS was conducted on a single-span single-floor plane frame in reference [30]. The frame was constructed by steel reinforced concrete columns and beams and reinforced concrete floor. The influence of the fire duration time, the axial compression ratio and load types on mid-span of beams to the seismic performance of the frame was analyzed. The results indicated that with the increasement of the load ratio on mid-span of the beams the frame stiffness could have minor changes. The frame structure after exposure to fire showed good energy-dissipation capacity under the condition of small axial compression ratio and shorter time of fire. The research mentioned above mainly focused on the inner joints, and the main contents were as follows: 1) monotonic loading or quasi-static loading tests on the joints after exposure to fire; 2) full-process analysis of load-displacement and parameter analysis; 3) evaluation method for residual bearing capacity after exposure to fire. Since the mechanical behavior and failure mechanism of the inner joint and the exterior joint as well as the corner joint were different. Furthermore, the damage evolution rule of the floor would have impacts on seismic performance of the joints behavior after exposure to fire. Therefore, research in this aspect need to be strengthened in future study.

\subsection{Research and Development Prospect}

Based on the study and analysis on the damage mechanism and residual mechanical property of the composite structure after exposure to fire, the following areas need to have an intensive study in future.

\subsubsection{Performance Research on Composite Structure with Special Shaped Section After Exposure to Fire}

Concrete structure with specially shaped columns are widly used in practical projects in recent years. The advantages of this kind of structure are flexible construction, low cost and with large indoor effective area. Especially with the emergence of large complex ultrahigh-rise buildings, the mega composite columns with special-shaped section has been adopted to meet the functional requirements of the building. Compared with the ordinary steel concrete composite structure, the composite structure with special shaped section has higher steel ratio and exposure area to fire. So, the composite structure with special shaped section is more likely to suffer from the damage in the same condition. For this purpose, it is necessary to study the mechanical properties, seismic performance and evaluation methodology after exposure to fire for the composite structure with special shaped section.

\subsubsection{Performance Research on High Strength Steel Concrete Composite Structure After Exposure to Fire}

High strength steel has been successfully used in multiple building structures and bridge structures for its high strength, good toughness and other advantages at home and abroad. Here, we believe that the yield strength standard value of the high strength steel is more than $460 \mathrm{MPa}$. Stainless steel as a kind of high strength steel has also been applied in composite structure and the experiments on concrete filled stainless steel square tube short columns was launched to study its mechanical property in reference [31]. In addition, tests on Q460 high strength steel column were conducted in references $[32,33]$. The test results indicated that the Q460 high strength steel column also has good 
seismic performance. Furthermore, the material property of the Q460 high strength steel under high temperature was also studied through the fire test in reference [34]. In order to improve the safety of building structures in fire, earthquake and so on, the use of high strength steel is imperative and this has been reflected in the newly revised design specification. Based on the study of the properties of high strength steel material, research on the failure mechanism and mechanical property of high strength steel reinforced concrete structure under or after the action of fire would provide scientific basis for engineering design.

\subsubsection{Effect of Floor Damage Evolution on Structure Performance}

In practical building structure, beams exist around the slab. At the end of the beam, the floor slab could participate in the work as the flange of the beam. Slab could increase the stiffness of the upper part of the beam end, so the beam end plastic hinge can not be fully formed and the ideal energy dissipation mechanism can not be achieved. Moreover, under the action of fire, the redistribution of the internal force would happen for the interaction between beam and slab. The mechanical property of the structure would also be different from that without considering the slab-beam interaction. However, the existing study does not consider the action of the slab and the reliability of the analysis was reduced. Therefore, it is necessary to enhance the study on the impact of the slab damage evolution rule on structure performance after exposure to fire in the future.

\section{CONSENT FOR PUBLICATION}

Not applicable.

\section{CONFLICT OF INTEREST}

The authors confirm that this article content has no conflict of interest.

\section{ACKNOWLEDGEMENTS}

This study was jointly sponsored by the National Science Foundation of China (Grant No: 51378302), the Science and Technology Development of Shandong Province, China (Grant No: 2013GSF12005), the Science and Technology Development Plan of Jinan city, China (the Innovation Plan of Universities and research institutes. Grant No: 201303085), the Natural Science Foundation of Shandong Province (ZR2015EQ017), the Doctoral Fund Project of Shandong Jianzhu University (XNBS1202), Science Project of the department of housing and urban construction (2014K2-027) and Science Project of the office of housing and urban construction (KY023).

\section{REFERENCES}

[1] J.H. Li, M.Z. Liu, and Y.F. Tang, "Experimental study on the mechanical properties of steel reinforced concrete beams after exposure to fire", China Civil Engineering Journal, vol. 44, no. 4, pp. 84-90, 2011.

[2] J.H. Li, M.Z. Liu, and H. Xiao, "Numerical simulating analysis for residual loading bearing capacity of steel reinforced concrete beams after exposure to fire", Xi'an University of Archives \& Technology, vol. 45, no. 4, pp. 470-478, 2013.

[3] J. Han, “The Mechanical Properties After Fire of Prestressed SRC Beams" M.S. thesis, University of Shandong Jianzhu, Jinan, ON, China, 2011.

[4] S.B. Li, "Experimental Study and Theoretical Analysis on Bearing Capacity of the Prestressed SRC Beams After Exposure to Fire" M.S. thesis, University of Shandong Jianzhu, Jinan, ON, China, 2012.

[5] H.J. Wang, "Experimental Research on Fire-Resistant Ability and Bearing Capacity of Lightweight Aggregate Concrete Composite Floor" M.S. thesis, University of Ningbo, Ningbo, ON, China, 2011.

[6] L.H. Han, Y.F. Yang, and J.S. Huo, "Tests on the residual strength of concrete filled steel tubular columns after exposure to fire", Engineering Mechanics, vol. 18, no. 6, pp. 100-109, 2001.

[7] J.S. Huo, "Behavior of Concrete-Filled Steel Tubular Beam-Columns After Standard Fire" M.S. thesis, Harbin Institute of Technology, ON, China, 2001.

[8] L.H. Han, and J.S. Huo, "Bearing capacity of concrete-filled steel tubular columns after fire", China Civil Engineering Journal, vol. 35, no. 4, pp. 25-35, 2002.

[9] L.H. Han, and J.S. Huo, "Concrete-filled hollow structural steel columns after exposure to ISO-834 fire standard", Structural Engineering of ASCE, vol. 129, no. 1, pp. 68-78, 2003. [http://dx.doi.org/10.1061/(ASCE)0733-9445(2003)129:1(68)]

[10] L.H. Han, H. Yang, and J.S. Huo, "Residual strength of concrete filled steel tubular columns with rectangular sections after exposure to standard fire", Engineering Mechanics, vol. 19, no. 5, pp. 78-86, 2002. 
[11] L.H. Han, Y.F. Yang, and H. Yang, "Residual strength of concrete-filled RHS columns after exposure to the ISO-834 standard fire", Thinwalled Structures, vol. 40, no. 12, pp. 991-1012, 2002. [http://dx.doi.org/10.1016/S0263-8231(02)00044-7]

[12] J.S. Huo, and L.H. Han, "Discussions on practical calculation of axial and flexural load versus deformation curves of CFST after exposure to fire", Industrial Construction, vol. 36, no. 11, pp. 6-10, 2006.

[13] N. Wang, "Mechanics Behavior Analysis and Application of CFST Frame Columns After Fire" M.S. thesis, Daqing Petroleum Institute, ON, China, 2003.

[14] J. Zhou, "Study on the Column Reinforced by Inner Circular Steel Tubes Under Axial Force in Normal Temperature and After Fire" M.S. thesis, Zhejiang University, ON, China, 2006.

[15] J. Zhou, "Research on temperature distribution and residual bearing capacity after exposure to fire of column reinforced by inner circular steel tube", Special Structures, vol. 26, no. 4, pp. 35-39, 2009.

[16] Y.H. Feng, T. Shen, and W.J. Lou, "The study of residual load bearing capacity of column reinforced by inner circular steel tube after fire", Industrial Construction, vol. 38, no. 3, pp. 16-19, 2008.

[17] W.L. Jin, and W.B. Yuan, "Analysis on resistance on and after exposure to standard fire of short centrifuge concrete-filled steel tubular columns", Zhejiang University, vol. 40, no. 7, pp. 1206-1210, 2006. [Engineering Science].

[18] D.P. Zou, "Study of the Residual Load Bearing Capacity of Steel-Concrete Axial Compression Columns After High Temperature". M.S. thesis, Suzhou University of Science and Technology, ON, China, 2009.

[19] J.X. Hou, and X.Y. Mao, "An experimental investigation on behavior of eccentric compression SRC columns after fire with heating-cooling effect", Suzhou University of Science and Technology (Engineering and Technology), vol. 23, no. 4, pp. 21-25, 2010.

[20] J.H. Li, Y.F. Tang, and M.Z. Liu, "Experimental study on mechanical properties of steel reinforced concrete columns after exposure to fire", Journal of Building Structures, vol. 33, no. 2, pp. 56-63, 2012.

[21] J.H. Li, Y.H. Zhao, and Y.F. Tang, "Experimental study on residual load bearing capacity of SRC columns under axial force after exposure to fire", Engineering Mechanics, vol. 29, no. S1, pp. 86-91, 2012.

[22] L.H. Han, and X.K. Lin, "Tests on cyclic behavior of concrete-filled hollow structural steel columns after exposure to the ISO-834 standard fire", Structural Engineering of ASCE, vol. 130, no. 1, pp. 1807-1819, 2004. [http://dx.doi.org/10.1061/(ASCE)0733-9445(2004)130:11(1807)]

[23] X.K. Lin, and L.H. Han, "Cyclic analysis of concrete filled square hollow section columns after exposure to ISO-834 standard fire", Earthquake Engineering and Engineering Vibration, vol. 25, no. 3, pp. 104-109, 2005.

[24] X.K. Lin, "Cyclic Performance of Concrete-Filled Steel Tubular Column After Exposure to Fire" Ph.D.thesis, Fuzhou University, ON, China, 2006 .

[25] X. Zeng, "Experimental Research on Cyclic Behavior of Concrete-Filled Steel Tubular Columns with Sustained Axial Load After Exposure to Fire". M.S.thesis, Hunan University, ON, China, 2009.

[26] J.S. Huo, X. Zeng, and Y. Xiao, "Cyclic behavior of concrete-filled steel tubular columns with pre-load after exposure to fire", Constructional Steel Research, vol. 67, no. 4, pp. 720-726, 2011. [http://dx.doi.org/10.1016/j.jcsr.2010.11.005]

[27] J.S. Huo, "Behavior of Steel Beam to Concrete-Filled Steel Tubular Column Connections After Exposure to Fire". Ph.D. thesis, Fuzhou University, ON, China, 2005.

[28] J.S. Huo, and L.H. Han, "Hysteretic behavior of steel beam to concrete-filled steel tubular column connections after exposure to fire", Building Structures, vol. 27, no. 6, pp. 28-38, 2006.

[29] T.Y. Song, "Research on Post-Fire Performance of Steel-Concrete Composite Beam-Column Joints" Ph.D. thesis, Tsinghua University, ON, China, 2010.

[30] F.D. Xie, Z.X. Wu, and D.D. Liu, "Anti-seismic performance finite element analysis of steel reinforced concrete frame after fire", Journal of Beijing University of Civil Engineering and Architecture, vol. 29, no. 3, pp. 35-39, 2013.

[31] D. Lam, and K.Y. Wong, “Axial capacity of concrete filled stainless steel columns”, Structures Congress of ASCE, 2005, pp. 1-11. [http://dx.doi.org/10.1061/40753(171)105]

[32] B. Liu, W.Y. Wang, and G.Q. Li, "Study of fire resistance of high strength Q460 steel columns", China Civil Engineering Journal, vol. 45, no. 9, pp. 19-26, 2012

[33] F.F. Sun, L.M. Xie, and W. Cui, "Experimental study on material properties of Q460 high strength steel under monotonic and cyclic loading", Building Structures, vol. 34, no. 1, pp. 30-36, 2013.

[34] G.Q. Li, Y.B. Wang, and S.W. Chen, "Experimental study of Q460C high strength steel welded H-section and box-section columns under cyclic loading", Building Structures, vol. 34, no. 3, pp. 80-86, 2013.

\section{(C) 2017 / IXHWWO}

This is an open access article distributed under the terms of the Creative Commons Attribution 4.0 International Public License (CC-BY 4.0), a copy of which is available at: https://creativecommons.org/licenses/by/4.0/legalcode. This license permits unrestricted use, distribution, and reproduction in any medium, provided the original author and source are credited. 